\title{
The Development of Module for 5-axis Drilling of a Closed Type Impeller
}

\author{
Hwang-Jin Son*, Yoon-Tea cho**, Yoon-Gyo Jung \# \\ ( *,**, \# Department of Mechanical Engineering, Changwon National Univ., ) \\ 밀폐형 임펠러의 5축 드릴링 모듈의 개발 \\ 손황진*, 조영태**, 정윤교\# \\ (Received 24 January 2014; accepted 18 February 2014)
}

\begin{abstract}
An impeller is difficult to machine due to the complex, overlapping and twisted shapes that form the blades of an impeller. Therefore, most CAM software companies have developed a CAM module for manufacturing an impeller in addition to their CAM software. However, it is not easy for inexperienced users to machine impellers. The purpose of this paper is to outline the development of an automatic CAM module for the manufacturing of an impeller (E-ICAM) which is based on visual basic language and which uses a CATIA graphical environment in order to simplify the machining of impellers. The automatic CAM module generates a tool path and proposes the recommended cutting condition according to the stock and tool material. In addition, it includes a post-processor for five-axis control machining. Therefore, a user can easily machine impellers using this automation module. There are two types of impellers: the closed and open types. The closed-type impeller consists of the body and cover parts. To combine these two parts, it is necessary to create tap holes on the shroud of the body. Therefore, in the study, a drilling CAM program for a closed-type impeller is developed and manufactured by creating NC data from the developed drilling program. After manufacturing the test specimen, its compatibility was verified.
\end{abstract}

Key Words : E-ICAM(Easy Impeller CAM), Impeller(임펠러), 5-axis Control Machining(5축가공), Cutting Condition(절삭조건), Post-Processor(포스트프로세서), Drilling(드릴링)

\footnotetext{
* Department of Mechanical Engineering, Changwon national University

** Department of Mechanical Engineering, Changwon national University

\# C. A. : Department of Mechanical Engineering, Changwon national University

E-mail : ygjung@changwon.ac.kr
}

\section{Introduction}

Impellers, which are used as the core component in generators, pumps, turbines, turbochargers etc. can be divided into open type impellers and closed type impellers. The closed type impeller is composed of a body and cover, and the closed type is used for equipment which generates higher speed and higher 
pressure than the open type. The impeller is used in the industrial sector in general, but machining path generation is hard work for production, so studies on program development, including tool path generation for machining ${ }^{[1-8]}$ and the development of a post process machining apparatus are being actively carried out ${ }^{[9]}$. But studies on the five-axis drilling process program development about the free surface which should be accompanied essentially for machining the closed type impeller are insufficient.

Therefore, this study aims to develop a five-axis drilling automation module based on the graphical environment and Visual Basic of the CATIA program, and to load it with the easy Impeller CAM module(E-ICAM $)^{[10]}$ to allow an unskilled worker to more easily approach impeller machining.

\section{Five-axis machining process}

The five-axis machining process is divided into three segments the cutting condition, tool path generation and post processor, and the drilling process is the last process of the tool path generation. In the final process, 5-axis drilling work, it is necessary to combine a closed-type impeller body and curve, and as it is done on a free-formed surface, the program should generate Cutter Location (CL) data. The objective is a 5-axis drilling processing module for a closed-type impeller for which even a beginner can generate $\mathrm{CL}$ data with simple operation. It consists of a main frame, tool path generation and a drilling module.

When the recommended cutting conditions in the 5-axis drilling are decided, a tool path will be generated. CL data is generated by a program that generates a drilling tool path. The process of drawing the CL data is as follows. First, Cutter Contact (CC) data, the coordinate of the contact point between the material and the tool is generated, and the $\mathrm{CC}$ data is added to the Cutter Posture Vector. which is

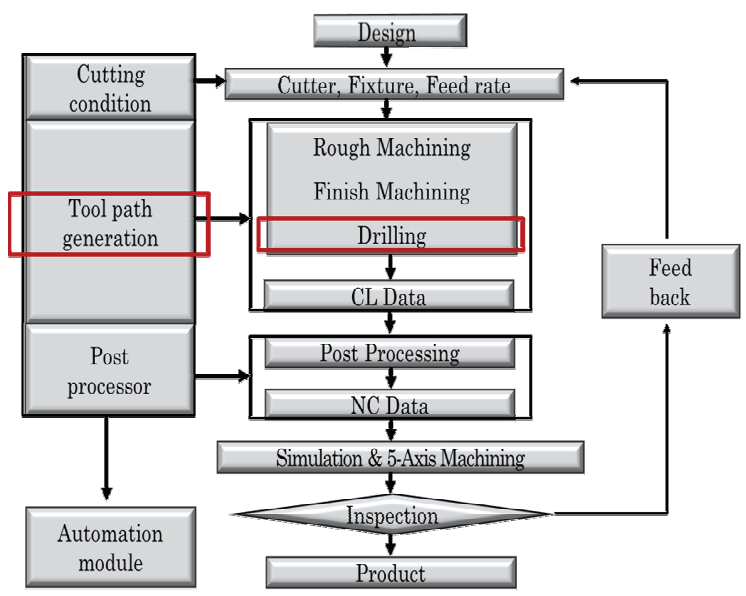

Fig. 1 Machining process of closed type impeller.

destined to become Cutter Location (CL) data. To drive the 5-axis processing machine using this $\mathrm{CL}$ data, it is necessary to convert it to Numerical Control (NC) data. This working process is called post processing. Fig. 1 presents the flowchart of the five-axis machining process.

\section{Composition of drilling module}

\subsection{Frame composition of drilling module}

The main frame is composed of a menu tool bar which conveys each sub module and function of connection, and it is linked with the tool path generation sub module, and it is composed of three status windows showing output $\mathrm{CC}$ data, tool posture vector, and CL data. Fig. 2 shows the frame composition of the module.

The tool path generation sub-module is roughing, and finishing, and consists of the drilling process. Fig. 3 is the execution screen of the five-axis machining path generation program for the drilling machining. The program is divided into the cover and body mainly for preparing the machining program. In detail, for the drilling process, the processes were subdivided into a center drilling 


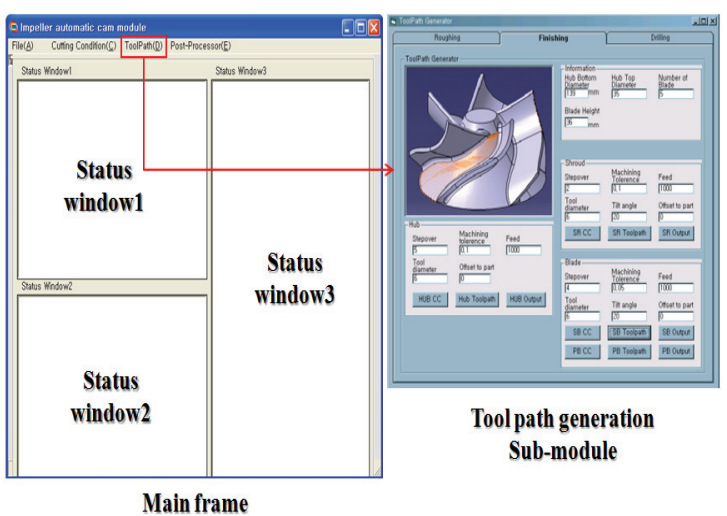

Fig. 2 Composition of module.

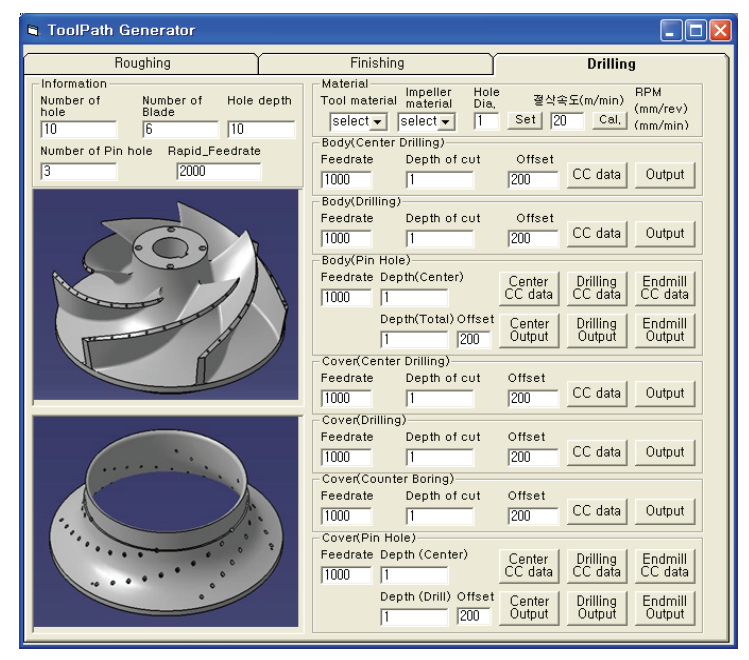

Fig. 3 Drilling sub-module.

process of positioning, drilling process of hole work, pin hole process for accurate combination after processing and counter boring process to hide the screw head.

\subsection{Recommended cutting conditions}

For an inexperienced worker the biggest issue with cutting machining is selecting the cutting conditions. To allow the inexperienced worker to select cutting conditions easily, the worker should be able to select them with a simple input value, by mounting the recommended cutting conditions presented in the
Table 1 Cutting condition ranges

\begin{tabular}{|c|c|c|}
\hline Tool matrial & Impeller matrial & Drill diameter \\
\hline \multirow{3}{*}{ HSS } & Steel & \multirow{3}{*}{$\begin{array}{l}2,3,4,5,6,7,8,9,10,12 \\
14,16,18,20,2224,26 \\
28,30,35,40,45,50\end{array}$} \\
\hline & Casting & \\
\hline & Aluminium & \\
\hline \multirow{3}{*}{$\begin{array}{l}\text { Sintered } \\
\text { carbide }\end{array}$} & Steel & \multirow{3}{*}{$\begin{array}{l}4,5,6,7,8,9,10,12,14 \\
16,18,20,22,24,26\end{array}$} \\
\hline & Casting & \\
\hline & Aluminium & \\
\hline
\end{tabular}

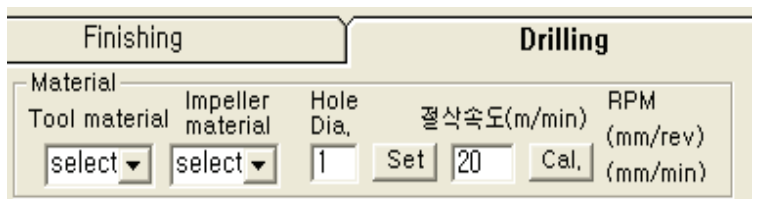

Fig. 4 Recommended drilling conditions.

module. Those results have been obtained through numerous experiments and studies on recommended cutting conditions. This paper chose the research results $^{[11]}$ as recommended cutting conditions and built a database. Table 1 shows the range of input of the recommended cutting conditions for drilling.

Three basic input values the material of the tool, that of the workpiece material and the diameter of the drill, as in Table 1 are entered, to select a recommended cutting condition corresponding to the input values. The resulting values the revolution per minute of the drill, Feed rate per revolutions and Feed rate per minute are displayed. Fig. 4 is a picture of the module where the basic input values are entered as a part of the drilling module.

\section{Development of drilling program}

\subsection{Drilling tool posture vector}

The tool posture vector of the drill is needed for five-axis drilling machining. Cutter Posture Vector is a very important element as an axis to set the 


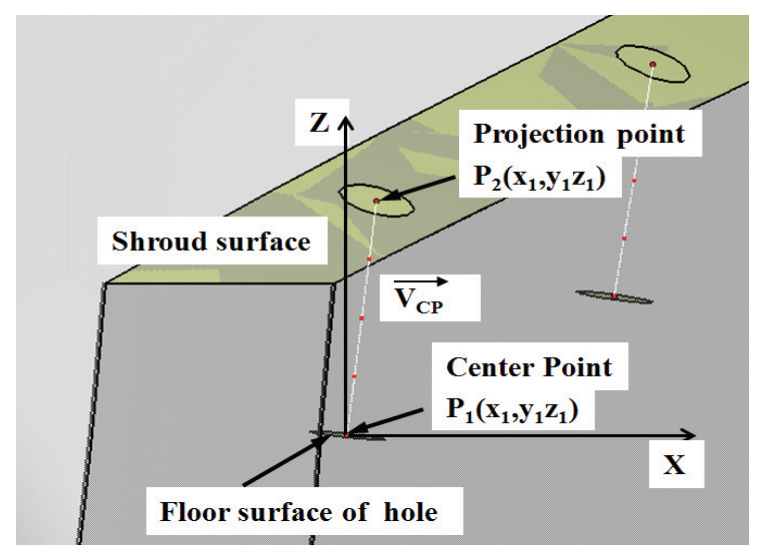

Fig. 5 Cutter posture vector of drilling.

posture of the drill for drilling work. If the axis of the drilling work inclines, the work deviates from the Shroud surface to cause a fault on the product. Thus, the Cutter Posture Vector falls to the depth of drilling as shown in Fig. 5, which generates Center Point $\mathrm{P}_{1}$ at the floor surface of the drill formed on the surface vertical to the blade. And it projects $P_{1}$ vertically to the floor surface of the drill and generates $\mathrm{P}_{2}$ at the point at which it contacts the Shroud surface. The generated vector connecting Points $P_{1}$ and $P_{2}$ is the Cutter Posture Vector $\left(V_{c p}\right)$. The unit vector of $V_{c p}$ can be calculated with Formula(1).

$$
\overrightarrow{V_{c p}}=\frac{\overrightarrow{P_{1} P_{2}}}{\left|\overrightarrow{P_{1} P_{2}}\right|}
$$

\subsection{Generation techniques of $\mathrm{CC}$ data}

A closed type impeller is composed of a body and cover, so each have different conditions that should be considered for recognition of the machining region. First, for the body part processing area, connect the Point $\mathrm{P}_{2}$ extracted from (a) Shroud surface and the Point $\mathrm{P}_{1}$ extracted from (b) floor surface in a straight line, as in Fig. 6. Then, generate points from the starting point of the drill

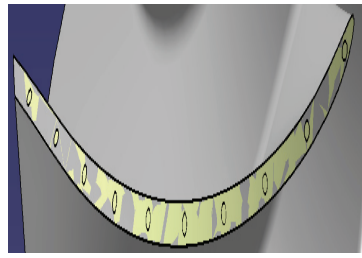

(a) Shroud surface

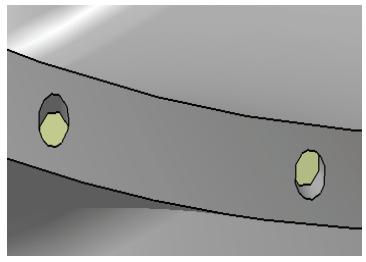

(b) Floor surface of hole
Fig. 6 Boundary condition of body part.
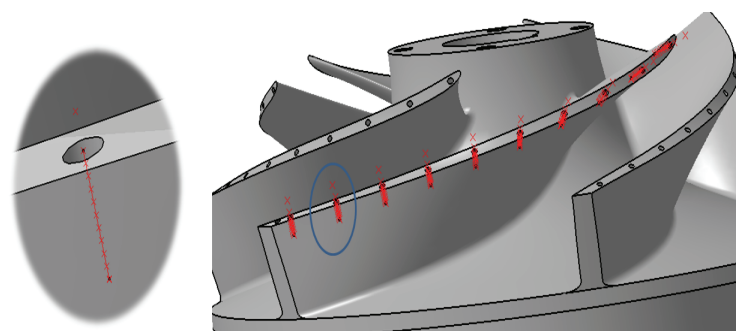

Fig. 7 Generation of CC, CL data for body part drilling.

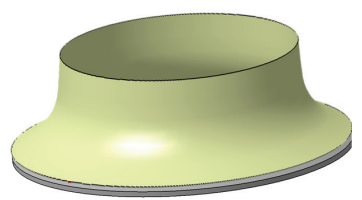

(a) Upper surface

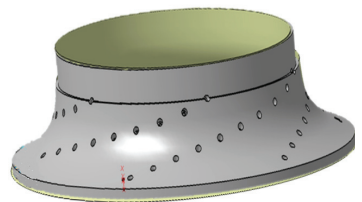

(b) Lower surface
Fig. 8 Selection of machining region for cover.

processing dividing the straight line to the end point $\left(\mathrm{P}_{1}\right)$ at equal intervals. The intervals of the points generated at equal intervals are the depths of cut, and the user can control the amount of depth of cut by setting it as a variable in the module of the program. The coordinates of the points are CC data. Fig. 7 shows the extracted points.

Next, select the central axis of the hole in the model to generate the $\mathrm{CL}$ data of the cover part, which is the Cutter Posture Vector. Generate points, respectively at the points at which the (a) Upper surface and (b) Lower surface in Fig. 8 intersect 

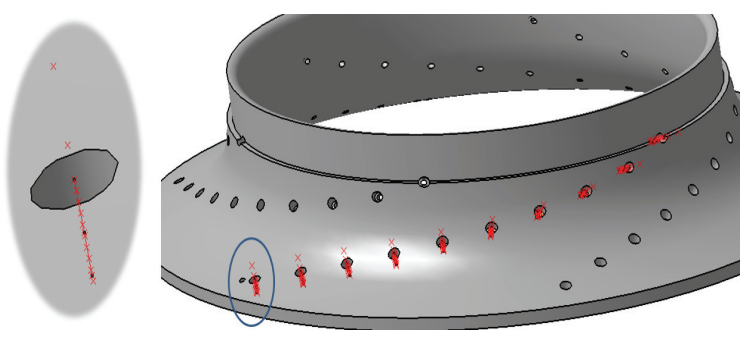

Fig. 9 Generation of CC, CL data for cover part drilling.

with the Cutter Posture Vector. The points generated are the start point and end point of drilling, and the coordinates of the points divided at equal intervals based on them are CC data. The size of the equal intervals is the amount of depth of cut per time which is determined by the user. Fig. 9 shows the extracted points.

\section{Verification of development module}

For verification of the developed drilling module, the reliability of the developed five-axis drilling machining module was established by conducting machining simulation and prototype manufacture. The program used for the simulation used Vericut produced by United Kingdom CG Tech Corp, and the manufacture of a mock-up used a five-axis machine tool (M2) produced by Hwacheon Machinery Co., Ltd..

First, the simulation verification extracts the $\mathrm{CL}$ data from the developed five-axis drilling machining module, and it is converted into $\mathrm{NC}$ data corresponding to the mechanism of the five-axis machine tool M2 equipment through the Post-processing. The NC data carries out the simulation by Vericut, providing M2 the same environment. In the simulation, the uncut and the crashes of tool was verified preponderantly. Fig. 10 shows the results of the completed simulation. Satisfactory resulting values were drawn through the program simulation, so the prototype model was

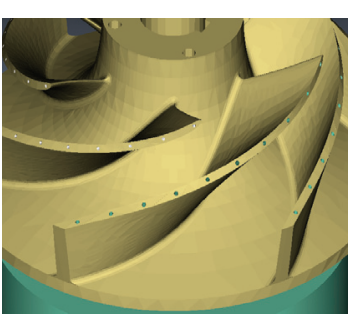

(a) Body part

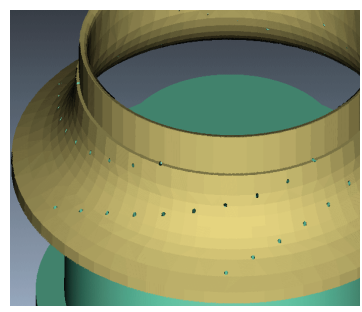

(b) Cover part
Fig. 10 Result of drilling simulation.

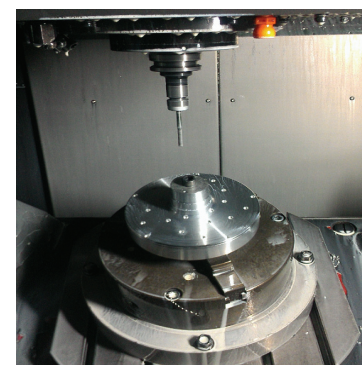

(a) 5-axis drilling

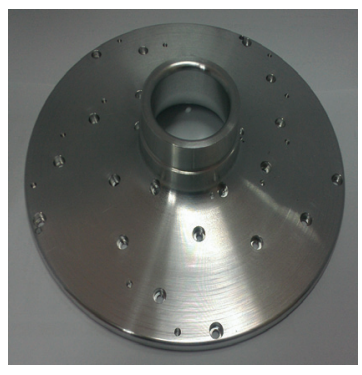

(b) Prototype (Cover)
Fig. 11 5-axis drilling using NC data generated by the E-ICAM.

produced. The spins revolution per minute for the prototype manufacture was 3000 RPM, and the prototype model cover was produced with cutting conditions feed rate of $100 \mathrm{~mm} / \mathrm{min}$. Fig. 11 shows the production of the prototype.

The drill machining of a closed type impeller is a slot operation for combining the body with a cover, so precise positioning is critically required for geometric tolerance. Consequently the position about the hole of the prototype model was measured by 3D measuring instrument. For measuring, a Global image 3D CMM produced by US Brown \& Sharp Company was used, and the measurement result is shown in Table 2. Looking at the result, the $\mathrm{X}$-axis average error was drawn as $0.039 \mathrm{~mm}$, and the average error of $\mathrm{Y}$-axis was $0.056 \mathrm{~mm}$. This error is considered to be due to the use of equipment but the error of the developed program. In addition, since the 
Table 2 Position error value

Unit(mm)

\begin{tabular}{c|c|c|c|c|c|c}
\hline & 1 & 2 & 3 & 4 & 5 & Ave. \\
\hline \hline $\mathrm{X}$ & 0.055 & 0.037 & 0.005 & 0.035 & 0.062 & 0.039 \\
\hline $\mathrm{Y}$ & 0.054 & 0.066 & 0.079 & 0.059 & 0.026 & 0.056 \\
\hline $\mathrm{Z}$ & 0.004 & 0.008 & 0.016 & 0.013 & 0.002 & 0.086 \\
\hline
\end{tabular}

general position tolerance of a hole necessary to manufacture an impeller on the spot is $0.1 \mathrm{~mm}$, the value of the measurement results are within the manufacturing tolerance. Therefore, the reliability of the developed drilling program can be confirmed through the two types of verification.

\section{Conclusion}

In this study, a five-axis drilling machining module for the inexperienced worker was developed to easily create $\mathrm{NC}$ data for the drill machining of an impeller, and the developed module was loaded in a five-axis CAM automatic module (E-ICAM) for the impeller.

An automatic module for a 5-axis drilling machine for manufacturing a closed type impeller was developed using the Visual Basic language. In order to increase the ability of unskilled workers to access drilling machining, the recommended cutting conditions were applied to the data base module. Finally, the reliability of the developed five-axis drilling module was confirmed by simulation verification and manufacture of prototype.

\section{References}

(1) Jang, D. K., Cho, H. Y., Lee, H. K., Kong Y. S., and Yang, G. E., "A study on tool path generation for machining impellers with 5-axis machining center", Journal of the Korean Society of Precision Engineering, Vol. 21, No. 3, pp. 83-90, 2004.

(2) Cho, H. Y., Jang, D. K., Lee, H. K., and Yang, G. E., "A study on efficient roughing of impellers with 5-axis NC machine", Journal of the Korean Society of Mechanical Engineering, Vol. 27, No. 11, pp. 1917-1924, 2003.

(3) Jang, D. K., Shin, J. K., Hong, S. K., Lee, H. K., and Yang, G. E., "A study on reverse engineering and 5-axis $\mathrm{NC}$ machining of impeller", Journal of the Korean Society of Precision Engineering, Vol. 21, No. 6, pp. 60-68, 2004.

(4) Jang, D. K., Lim, K. N., and Yang, G. E., "A study on five-axis roughing of impeller with ruled surface", Journal of the Korean Society of Precision Engineering, Vol. 24, No. 7, pp. 60-68, 2007.

(5) Oh, J. Y., Hwang, J. D., Jung, H. C., and Jung, Y. G., "The Effect of Surface Roughness of Impeller by Tool Path and Posture", 2008 Autumn Conference of KSPE, pp. 347-348, 2008.

(6) Lee, K. Y., Kim, H. M., Park, S. S., and Jang, K. C., "The Determination of cutting conditions and machining process in 5-axis machining of a impeller", Conference of KSME, No. 6, pp. 1471-1474, 2006.

(7) Park, K. B., Jung, H. C., Hwang, J. D., and Jung, Y. G., "A Continuous Control of Cutter Posture Change for Efficient 5-axis Machining of Impeller", Autumn Conference of KSMPE, Vol. 2010, No. 11, pp. 33-34, 2010.

(8) Hwang, J. D., Jung, H. C., and Jung, Y. G., "Continuity control method of cutter posture vector for efficient five-axis machining", Journal of Central South University of Technology, Vol. 18, No. 6, pp. 1969-1975, 2011.

(9) Jung, H. C., Hwang, J. D., Kim, S. M., and Jung, Y. G., "The post processor technology for 5 -axis control machining", Journal of the Korean Society of Manufacturing Process Engineering, 
Vol. 10, No. 2, pp. 9-15, 2011.

(10) Jung, H. C., Son, H. J., and Jung, Y. G.

"Development of too-path generation module for

5-axis control machining of impeller", Journal of

Central South University, Vol. 19, No. 12, pp.

1969-1975, 2011.

(11) Kwon, D. H., CNC programs for machining,

Yeamoonsa, pp. 414-415, 2008. 